\title{
Monitoring of cyanotoxins in water from hypersaline microalgae colonies by ultra high performance liquid chromatography with diode array and tandem mass spectrometry detection following salting-out liquid-liquid extraction
}

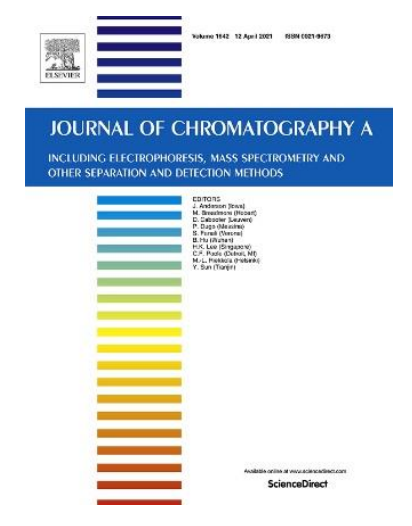

\author{
Maryam Hemmati ${ }^{(1,2)}$, Carmen Tejada-Casado ${ }^{(1)}$, Francisco J. Lara ${ }^{(1)}$, Ana M. \\ García-Campaña ${ }^{(1)}$, \\ Maryam Rajabi ${ }^{(2)}$, Monsalud del Olmo-Iruela ${ }^{(1) *}$ \\ (1) Dept. of Analytical Chemistry, University of Granada, Av. Fuente Nueva s/n, \\ 18071, Spain \\ (2) Department of Chemistry, Semnan University, Semnan 2333383-193, Iran \\ *mdolmo@ugr.es, Tel: +34-958-249-678, Fax: +34-958-243-328
}

\section{Preprint version. Please cite original version:}

Hemmati, M., Tejada-Casado, C., Lara, F. J., García-Campaña, A. M., Rajabi, M., \& del Olmo-Iruela, M. (2019). Monitoring of cyanotoxins in water from hypersaline microalgae colonies by ultra high performance liquid chromatography with diode array and tandem mass spectrometry detection following salting-out liquid-liquid extraction. Journal of Chromatography A, 1608, 460409. https://doi.org/10.1016/j.chroma.2019.460409 


\begin{abstract}
In this study two different analytical approaches have been developed to determine the presence of several cyanotoxins in saline water samples from a continental salt marsh. A salting-out assisted liquid-liquid extraction (SALLE) has been used in combination with ultra-high performance liquid chromatography-tandem mass spectrometry and UV-diode array detection (UHPLC-MS/MS and UHPLC-DAD). The target analytes are eight microcystins named MC-RR, MC-YR, MC-LR, MC-WR, MC-LA, MC-LY, MC-LW, MC-LF and nodularin (NOD), covering a wide range of polarities. The separation was achieved using a Zorbax Eclipse Plus RRHD C18 column $(50 \times 2.1 \mathrm{~mm}, 1.8 \mu \mathrm{m})$ in less than 7.5 and $5.5 \mathrm{~min}$ for UV and MS/MS detection, respectively. The mobile phase used consisted of water (solvent A) and acetonitrile (MeCN) (solvent B), both containing $0.01 \%$ of formic acid for DAD and $0.4 \%$ of formic acid for MS/MS detection, at a flow rate of $0.4 \mathrm{~mL} \mathrm{~min}^{-1}$. The temperature of the column was set at $25^{\circ} \mathrm{C}$ and 20 $\mu \mathrm{L}$ of sample were injected. The main parameters affecting the SALLE procedure were studied and the following optimum values were obtained: neutral $\mathrm{pH}, 2 \mathrm{~mL}$ of acetonitrile as extraction solvent and $1.2 \mathrm{~g}$ of ammonium sulfate as salting-out agent for $4 \mathrm{~mL}$ of water sample. The validation protocols for both methods were accomplished with real water samples obtaining LODs ranging from 1.0 to $3.4 \mu \mathrm{g} \mathrm{L}^{-1}$ and 0.02 to $0.11 \mu \mathrm{g} \mathrm{L}^{-1}$ for DAD and MS/MS respectively. Although the SALLE-UHPLC-DAD methodology is easier and cheaper than UHPLC-MS/MS significantly better detection limits were achieved with tandem mass spectrometry as well as allowing for unambiguous identification. Extraction recoveries were higher than $77.0 \%$ (except for MC-RR and NOD which were 53.2\% and 54.3, respectively) with satisfactory inter-day and intra-day precisions (RSD below 13.3\%).
\end{abstract}

Keywords: Cyanotoxins; Diode array detection; Salting-out assisted liquid-liquid extraction; Saline waters; Tandem mass spectrometry; Ultra-high performance liquid chromatography. 


\section{Introduction}

Cyanobacteria, the oldest microorganisms in the world with fossil evidence of a 3.5-billion-year history [1], are prokaryotic organisms that exist as natural inhabitants of diverse environments such as fresh, brackish and marine waters and even in the illuminated surfaces of rocks and soils and have the capacity to withstand adverse and extreme environmental conditions [2]. They form the basis of numerous aquatic and terrestrial food chains, and are finding multiples applications in biotechnology, for the production of biofertilizers, biocides, drugs or cosmetics [3]. Cyanobacteria have been reported to contain $30-50 \%$ crude protein, polysaccharides, and pigment nutrients [4] been a cheap alternative protein sources for human and animal feeds in addition to their interest as dietary supplements.

In spite of its excellent properties, cyanobacteria can also produce toxins, presenting a great diversity for both their chemical structure and toxicity. Each cyanotoxin can be produced by more than one species of cyanobacteria, just as the same species also has the ability to produce more than one toxin and thus greatly contaminate the final products [5]. These toxins have a great capacity to bioaccumulate in the cyanobacteria, microalgae and other materials present through adsorption processes. They are also resilient and can be transported by inert materials or dry food destined for human or animal consumption. Therefore, the final manufactured products from that biomass could be potentially dangerous.

Existing within cyanotoxins, microcystins (MCs) and nodularins (NODs) is a group of cyclic peptide toxins named hepatotoxins because the liver is the primary target in cases of animal and human poisonings [2]. The MCs are monocyclic heptapeptides with the formula cycle-(Dalanine ${ }^{1}-\mathrm{X}^{2}-\mathrm{DMeAsp} \mathrm{S}^{3} \mathrm{Y}^{4}-\mathrm{Adda}^{5}$-D-glutamate ${ }^{6}-\mathrm{Mdha}^{7}$ ) where $\mathrm{X}$ and $\mathrm{Y}$ are the variable amino acids at positions 2 and 4, resulting in the occurrence of multiple congeners. The NODs are monocyclic pentapeptides structurally similar to MCs, cyclo-(D-MeAsp ${ }^{1}-Z^{2}-$ Adda $^{3}$-Dglutamate ${ }^{4}-\mathrm{Mdhb}^{5}$ ) where second residue (Z) is L-arginine (Arg) in the nodularin- $R$ that is frequently found; in fact, when we talk about nodularin without a suffix it is referred to. The amino acid Adda, unique to cyanobacteria, is responsible for hepatotoxicity, via deactivation of serine/threonine phosphatases in the liver, ultimately leading to formation of hepatic tumors, hemorrhage, and even death [6].

Despite the high toxicity they present, there are relatively few established limits for cyanotoxins. The World Health Organization (WHO) recommends a safe limit for MC-LR of $1 \mu \mathrm{g} / \mathrm{L}$ in 
drinking water [7]. For recreational exposure to water, WHO proposes a limit of $20 \mu \mathrm{g}$ MC-LR as a moderate reference value for a health alert [8]. In addition, for food products WHO proposes a provisional Tolerable Daily Intake (TDI) for MC-LR of $2.4 \mu \mathrm{g}$ per day for a $60 \mathrm{~kg}$ human [9]. A review published by the EFSA [10] on the presence, exposure and toxicity of cyanotoxins in food, shows that the majority of the studies focus on the microcystins (MC) and especially on a single variant MC-LR of the more than one hundred variants identified to date. MCs are relatively polar cyanotoxins but some variants contain, in the variable part of the molecule, hydrophobic amino acids such as MC-LF and MC-LW that contain phenylalanine (F) and tryptophan (W) respectively instead of arginine (R) as in MC-LR. These more hydrophobic variants have, in many cases, greater toxicity and bioaccumulation capacity; therefore, they should be included in toxicity control and evaluation programs [11]. On the other hand the review reveals that the lack of availability of reliable analytical methods is one of the principal problems in the evaluation of the contamination of complex matrices with cyanotoxins.

Bioassays have been commonly applied for the determination of cyanotoxins at trace levels $[12,13]$; however, they do not provide precise information on the chemical nature, nor on the amounts of the toxins causing the effects.

Liquid chromatography with UV detection $[14,15,16]$ and mass spectrometry $[17,18]$ has been mostly the chosen techniques for routine analysis of microcystins in any matrix. Recently ultrahigh-performance liquid chromatography (UHPLC) using both triple-quadrupole mass spectrometry [19,20,21] for target toxins and high-resolution mass spectrometry (HRMS) with Q-Exactive orbital ion trap [22] for structural identification are replacing the previous methods given their greater efficiency and shorter analysis times.

Capillary electrophoresis has been used less often for the analysis of these compounds but has revealed the enormous potential of the technique given its high capacity to resolve isomers, the low volume of sample needed and the possibility of manufacturing microchips [23], among others aspects. Recently, $\mathrm{CE}$ has been coupled to a time-of-flight detector (ToF) for the separation and identification of four MCs (LR, YR, RR, LA) in environmental samples, obtaining results comparable to those obtained by LC / MS but in shorter time and much lower sample and solvent consumption [24].

Solid-phase extraction is mainly applied as a clean-up/enrichment procedure prior to final chromatographic analysis of cyanotoxins, in both off-line [14,25,26,27] and on-line [28,29,19] 
configurations. The development and utilization of sample treatment involving lower solvent consumption and shorter analysis time has become a trend in the last decade [30]. Liquid-phase microextraction (LPME) and salting-out assisted liquid-liquid extraction (SALLE) resulted from classic liquid-liquid extraction (LLE), in order to overcome the problems of LLE. SALLE is simple, fast, and results in extracts that are in an organic solvent that can be evaporated and reconstituted into a suitable solvent for chromatographic analysis [31].

In addition, most of the published methods are focused on freshwater ecosystems (lakes, ponds and reservoirs), due to the frequent development of blooms of cyanobacteria in those water bodies. In contrast, the scarcity of information on the presence of cyanotoxins outside those ecosystems is striking [32]. Given the ability of cyanobacteria to survive under harsh and extreme conditions of temperature, desiccation, salinity, and light irradiation, the development of methods that allow us to show their presence in these environments is of utmost importance.

The aim of the present study, as part of a long-term project, is to develop fast, easy and reliable methodologies for monitoring the presence of cyanotoxins in water samples from cultures of hypersaline microalgae in a continental saline marsh located in Granada (Spain). Dunaliella salina, a halophile green microalgae that occurs naturally in this salt marsh, is of great interest for commercial production. Due to its ability to create large amount of carotenoids it is extensively used in cosmetics and dietary supplements [33]. Other species coexist with it, the main ones being Dunaliella viridis as hypersaline microalgae and Geitlerinema sp (order oscillatoriales), Synechococcus salinarum (order synechococcales) and Aphanoteces halophytica (order chroococcales) as cyanobacteria [34]. So, in order to commercialize the production of microalgae for human and animal consumption as well as the salt produced, a quality and food safety protocol must be implemented.

In this study, two different methodologies based on UHPLC-DAD and UHPLC-MS/MS, following SALLE as sample treatment, have been optimized, for the first time, for trace determination of eight MCs and NOD in the water samples taken in different pools of the saline marsh.

\section{Experimental}

\subsection{Reagents and materials}


The cyanotoxins studied including microcystin-leucine-arginine (MC-LR $\geq 99 \%$ ), microcystinarginine-arginine (MC-RR $\geq 99 \%$ ), microcystin-leucine-alanine (MC-LA $\geq 95 \%$ ), microcystinleucine-phenylalanine (MC-LF $\geq 95 \%$ ), microcystin-leucine-tryptophan (MC-LW $\geq 95 \%$ ), microcystin-leucine-tyrosine (MC-LY $\geq 95 \%$ ), microcystin-tyrosine-arginine (MC-YR $\geq 95 \%$ ), microcystin-tryptophan-arginine (MC-WR $\geq 95 \%$ ) and nodularin (NOD $\geq 95 \%$ ) were supplied by Enzo Life Sciences, Inc. (Lausen, Switzerland). The general structure of these common variants of MC and nodularin are shown in Fig. 1.

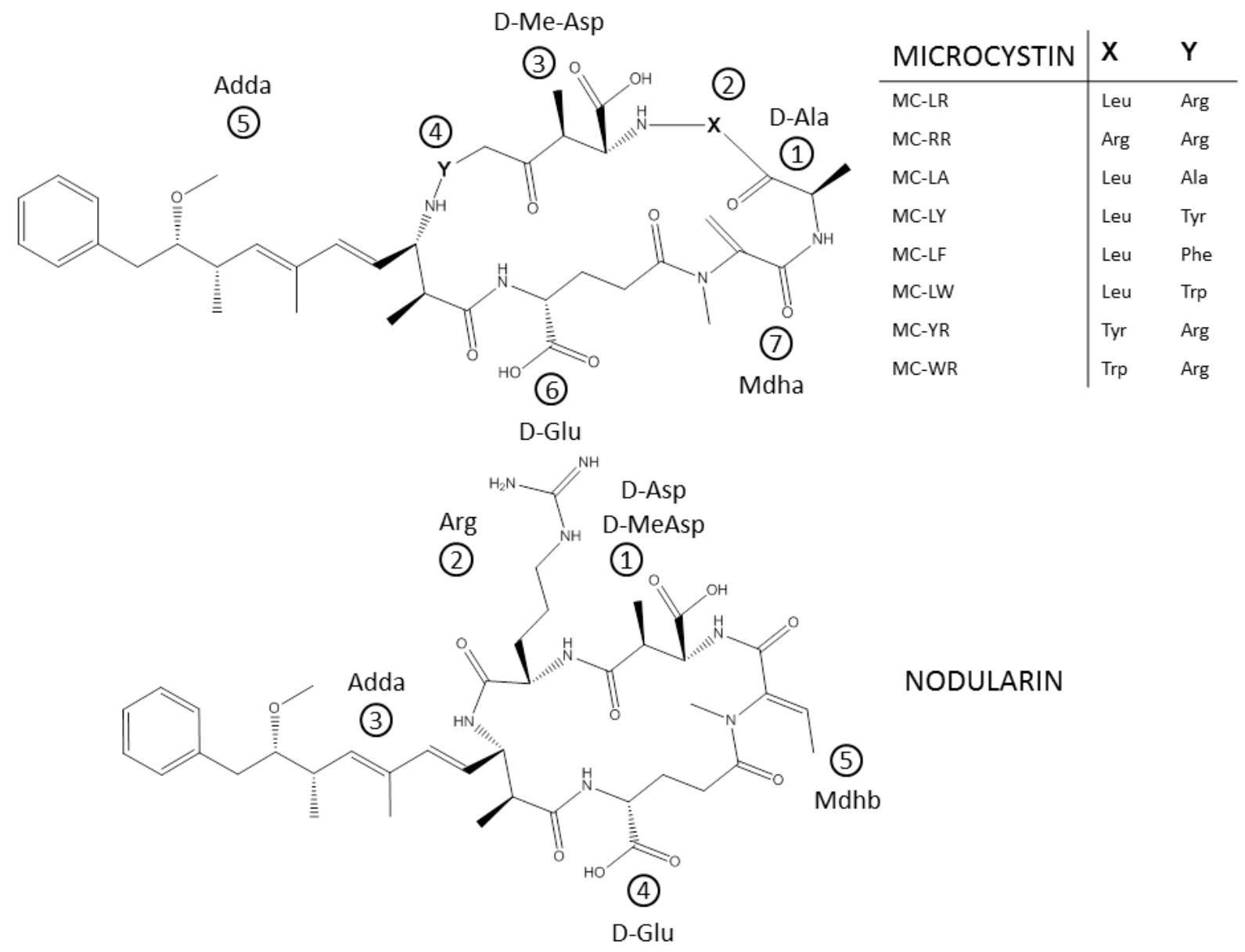

Fig 1. General structure of the eight common variants of $\mathrm{MC}$ and nodularin included in the study.

Acetonitrile $(\mathrm{MeCN})$, methanol $(\mathrm{MeOH})$, iso-propanol (IPA), tetrahydrofuran (THF), acetone (ACO), and ammonium sulfate $\left(\left(\mathrm{NH}_{4}\right)_{2} \mathrm{SO}_{4}\right)$ were purchased from VWR (Radnor, PA, USA). Magnesium sulfate anhydrous $\left(\mathrm{MgSO}_{4}\right)$ and sodium chloride $(\mathrm{NaCl})$ were obtained from Panreac (Barcelona, Spain). Formic acid (FA) and acetic acid (HAc) were purchased from Sigma-Aldrich 
(St. Louis, MO, USA). Ultra-pure water (Milli-Q plus system, Millipore, Bedford, MA, USA) was used throughout the work.

Stock standard solutions were prepared by drawing $1 \mathrm{~mL}$ of the desired solvent directly in the vial of toxin supplied by the manufacturer and gently swirling the vial to dissolve the toxin. The obtained solutions were: $50 \mu \mathrm{g} \mathrm{mL} \mathrm{m}^{-1} \mathrm{MC}-\mathrm{LR}$ in methanol, $25 \mu \mathrm{g} \mathrm{mL} \mathrm{m}^{-1} \mathrm{MC}-\mathrm{RR}$ in $80 \%$ aqueous $\mathrm{MeOH}, 25 \mu \mathrm{g} \mathrm{mL} \mathrm{mL}^{-1}$ of individual MC-LA, MC-LF, MC-LW, MC-LY,MC-YR, MC-WR in methanol, and $50 \mu \mathrm{g} \mathrm{mL}^{-1} \mathrm{NOD} 50 \%$ aqueous $\mathrm{MeOH}$. All of them were stored in the dark at $-20^{\circ} \mathrm{C}$.

Intermediate standard solutions for each compound at $2.5 \mu \mathrm{g} \mathrm{mL}^{-1}$ were prepared by dilution of the stock solutions with 80:20 v/v $\left(\mathrm{H}_{2} \mathrm{O}: \mathrm{MeOH}\right)$. These solutions were used daily to prepare the working solutions for UHPLC-MS/MS analyses.

One intermediate standard solution containing NOD and all the studied MCs at $2.5 \mu \mathrm{g} \mathrm{mL} \mathrm{m}^{-1}$ was prepared by dilution of the stock solutions with 80:20 v/v $\left(\mathrm{H}_{2} \mathrm{O}: \mathrm{MeOH}\right)$. This solution was diluted to the desired concentrations for UHPLC-DAD analyses.

PTFE $(0.2 \mu \mathrm{m} \times 13 \mathrm{~mm})$ and fiberglass $(0.7 \mu \mathrm{m} \times 13 \mathrm{~mm})$ syringe filters were purchased from VWR (Radnor, PA, USA). Nylon and PVDF syringe filters $(0.2 \mu \mathrm{m} \times 13 \mathrm{~mm})$, CA syringe filters $(0.45 \mu \mathrm{m} \times 13 \mathrm{~mm})$ were obtained from Bonna-Agela Technologies (Wilmington, DE, USA).

\subsection{Instrumentation}

A UHPLC 1290 Infinity II System (Agilent Technologies, Waldbronn, Germany) equipped with quaternary pump, degasser, autosampler, column thermostat and diode array detector (DAD) was used for chromatographic separation and UV detection of the aforementioned toxins. Agilent Mass Hunter Workstation Data Acquisition and Agilent Mass Hunter Qualitative Analysis Navigator B.08.00 softwares were used for data acquisition and processing.

A UHPLC Agilent 1290 Infinity System (Agilent Technologies, Waldbronn, Germany) consisting of a binary pump, a degasser, an autosampler (with a $20 \mu \mathrm{L}$ injection loop) a column thermostat coupled to a triple quadrupole (QqQ) mass spectrometer API 3200 (AB SCIEX, Toronto, ON, Canada) equipped with a Turbo V electro spray ionization probe (ESI) was also 
used for chromatographic separation and MS/MS detection. Data were collected and treated by Analyst ${ }^{\circledR}$ Software (version 1.5) using the Scheduled MRM ${ }^{\mathrm{TM}}$ Algorithm (AB SCIEX).

A Zorbax Rapid Resolution High Definition (RRHD) Eclipse Plus C18 column $2.1 \mathrm{~mm}$ x 50 mm, $1.8 \mu \mathrm{m}$ particle size (Agilent Technologies, Waldbronn, Germany) was utilized as chromatographic column for both setups. A Kinetex Biphenyl Core-Shell $(50 \mathrm{~mm} \times 2.1 \mathrm{~mm}$, $1.7 \mu \mathrm{m})$ column, a Kinetex HILIC $(100 \mathrm{~mm} \times 2.1 \mathrm{~mm}, 1.7 \mu \mathrm{m})$ column and a Luna Omega polar C18 (50 mm $\times 2.1 \mathrm{~mm}, 1.6 \mu \mathrm{m})$ column supplied by Phenomenex (Torrance, CA, USA) were also tested.

A vortex-2Genie (Scientific Industries, Bohemia, NY, USA), a Universal 320R centrifuge (Hettich, Leipzig, Germany), a nitrogen dryer EVA-EC System (VLM GmbH, Bielefeld, Germany), and a pH-meter (Crison model pH 2000, Barcelona, Spain), with a resolution of \pm $0.01 \mathrm{pH}$ unit, were also used through the sample treatment.

\subsection{UHPLC-UV conditions}

The mobile phase composition for the separation process was water/MeCN (A/B) both containing $0.01 \%$ of FA. The following gradient program was applied in order to accomplish the separation: 0 min, 25\%(v/v) B; 3min, 35\% B; $5 \min , 55 \%$ B; 6 min, 90\% B; 8min, 90\% B; 10 $\min , 25 \% \mathrm{~B}, 12 \mathrm{~min}, 25 \% \mathrm{~B}$. At $10 \mathrm{~min}$ mobile phase composition was back to initial conditions. In order to achieve column equilibration for the next run, the initial conditions were maintained

for $2 \mathrm{~min}$. Mobile phase flow rate was $400 \mu \mathrm{L} \mathrm{min}{ }^{-1}$. Column temperature was set to $25^{\circ} \mathrm{C}$, an injection volume of $20 \mu \mathrm{L}$ was used and samples were injected in 25:75\% (v/v) $\mathrm{MeCN}: \mathrm{H}_{2} \mathrm{O}$ both containing $0.01 \%$ of FA. The absorbance was measured at a fixed wavelength of $240 \mathrm{~nm}$ (bandwidth $4 \mathrm{~nm}$ ).

\subsection{UHPLC-ESI-MS/MS conditions}

The mobile phase involved in the separation process was water/MeCN (A/B) both containing $0.4 \%$ of FA as volatile acid. The gradient elution program applied was the same described above. The other chromatographic parameters used also coincide with those described for UHPLC-UV. Sensitive MS/MS quantification was conducted via ESI in positive ion mode under the MRM conditions. The TurboV ion source parameters were: curtain gas (CUR) (nitrogen) pressure, 30 
psi; ion source temperature(TEM), $400^{\circ} \mathrm{C}$; ions spray voltage(IS), $4750 \mathrm{~V}$; collision gas pressure (CAD), 15 psi; and Gas 1 (nitrogen nebulizer gas) and Gas 2 (nitrogen heater gas) pressures, 50 psi, following the recommendation of the manufacturer. Main parameters of MRM for all toxins are given in Table 1.

Table 1. MRM characteristics of the cyanotoxins based on main ion transitions.

\begin{tabular}{|c|c|c|c|c|c|c|c|c|}
\hline Compound & $\begin{array}{l}\text { Retention } \\
\text { time(min) }\end{array}$ & $\begin{array}{l}\text { Precursor } \\
\text { Ion }(\mathbf{m} / \mathbf{z})\end{array}$ & $\begin{array}{c}\text { Product } \\
\text { Ions }\end{array}$ & $\mathbf{D P}(\mathrm{V})$ & $\mathbf{E P}(V)$ & $\operatorname{CEP}(V)$ & $\mathbf{C E}(\mathrm{V})$ & $\operatorname{CXP}(V)$ \\
\hline \multirow{2}{*}{ MC-RR } & \multirow{2}{*}{1.80} & \multirow{2}{*}[\mathrm{M}+2\mathrm{H}]{$^{2+}, 519.8$} & \multirow{2}{*}{$\begin{array}{r}135.2(\mathrm{Q}) \\
103.2(\mathrm{I}) \\
\end{array}$} & \multirow{2}{*}{$\begin{array}{l}41 \\
41\end{array}$} & \multirow{2}{*}{$\begin{array}{l}6.0 \\
6.0\end{array}$} & \multirow{2}{*}{18} & 39 & 4 \\
\hline & & & & & & & 91 & 6 \\
\hline \multirow[t]{2}{*}{ NOD } & \multirow{2}{*}{2.60} & \multirow{2}{*}[\mathrm{M}+\mathrm{H}]{$^{+}, 825.4$} & $135.1(\mathrm{Q})$ & 106 & 8.0 & \multirow{2}{*}{24} & 79 & 6 \\
\hline & & & $70.1(\mathrm{I})$ & 60 & 10.0 & & 45 & 4 \\
\hline \multirow{2}{*}{ MC-YR } & \multirow[t]{2}{*}{3.10} & \multirow{2}{*}[\mathrm{M}+\mathrm{H}]{$^{+}, 1045.5$} & \multirow{2}{*}{$\begin{array}{c}135.2(\mathrm{Q}) \\
70.2(\mathrm{I})\end{array}$} & \multirow{2}{*}{$\begin{array}{l}131 \\
131 \\
\end{array}$} & \multirow{2}{*}{$\begin{array}{l}11.0 \\
11.0 \\
\end{array}$} & \multirow{2}{*}{34} & 95 & 6 \\
\hline & & & & & & & 117 & 6 \\
\hline \multirow{2}{*}{ MC-LR } & \multirow[t]{2}{*}{3.40} & \multirow{2}{*}[\mathrm{M}+\mathrm{H}]{$^{+}, 995.5$} & $135.3(\mathrm{Q})$ & 116 & 8.0 & \multirow{2}{*}{34} & 83 & 6 \\
\hline & & & $127.3(\mathrm{I})$ & 116 & 8.0 & & 115 & 4 \\
\hline \multirow[t]{2}{*}{ MC-WR } & \multirow[t]{2}{*}{3.86} & \multirow{2}{*}[\mathrm{M}+\mathrm{H}]{$^{+}, 1068.5$} & $135.2(\mathrm{Q})$ & 41 & 11.0 & \multirow{2}{*}{32} & 93 & 6 \\
\hline & & & $159.2(\mathrm{I})$ & 41 & 11.0 & & 89 & 6 \\
\hline \multirow{2}{*}{ MC-LA } & \multirow[t]{2}{*}{4.76} & \multirow{2}{*}[\mathrm{M}+\mathrm{H}]{$^{+}, 910.2$} & $135.1(\mathrm{Q})$ & 46 & 9.5 & \multirow{2}{*}{32} & 69 & 6 \\
\hline & & & 213.2(I) & 46 & 9.5 & & 109 & 6 \\
\hline \multirow{2}{*}{ MC-LY } & \multirow[t]{2}{*}{4.85} & \multirow{2}{*}[\mathrm{M}+\mathrm{H}]{$^{+}, 1002.5$} & $135.2(\mathrm{Q})$ & 66 & 10.0 & \multirow{2}{*}{32} & 73 & 6 \\
\hline & & & $127.2(\mathrm{I})$ & 66 & 10.0 & & 103 & 6 \\
\hline \multirow{2}{*}{ MC-LW } & 5.23 & {$[\mathrm{M} \perp \mathrm{H}]+10255$} & $135.2(\mathrm{Q})$ & 56 & 7.5 & 32 & 89 & 6 \\
\hline & & {$[101+\pi], 1025.5$} & $107.2(\mathrm{I})$ & 56 & 7.5 & 52 & 115 & 6 \\
\hline & 5.35 & & $135.2(\mathrm{Q})$ & 56 & 7.5 & & 81 & 6 \\
\hline $\mathrm{MC}-\mathrm{LF}$ & & [N & 213.1(I) & 56 & 7.5 & 38 & 115 & 6 \\
\hline
\end{tabular}

Q: quantification ion; I: identification ion; DP: declustering potential; EP: entrance potential; CEP: collision energy; CXP: collision cell exit potential.

\subsection{Extraction procedure}

Water samples were taken from two storage tanks with different salinity (Type A $19^{\circ}$ Baume, Type B $21^{\circ}$ Baume) in the continental salt marsh located in the Malahá (Granada, Spain). The samples were filtered with PTFE $(0.2 \mu \mathrm{m} \times 13 \mathrm{~mm})$ and stored at $-20{ }^{\circ} \mathrm{C}$ until analysis.

The proposed sample treatment consisted of two main stages:1) A SALLE procedure by a polar/water-miscible organic solvent in a salty medium assisted by high-speed centrifugation and 2) drying/redissolving the extract in a small volume of the mobile phase at the initial composition.

$4 \mathrm{~mL}$ of aqueous sample were poured into a $10.0 \mathrm{~mL}$ glass tube and then spiked with a certain volume of the intermediate standard solution. Afterwards, $2.0 \mathrm{~mL}$ of $\mathrm{MeCN}$ as extraction solvent 
was added, followed by vortex agitation for $1 \mathrm{~min}$. In order to separate the water-miscible organic solvent, $1.2 \mathrm{~g}$ of $\left(\mathrm{NH}_{4}\right)_{2} \mathrm{SO}_{4}$ was added to the sample and then shaken for $1 \mathrm{~min}$ again. After that, the mixture was centrifuged at $9000 \mathrm{rpm}$ for $5 \mathrm{~min}$, causing the organic phase to partition in the upper level. A volume of $1.5 \mathrm{~mL}$ of the organic phase was adequately collected and transferred to a $4 \mathrm{~mL}$ vial. Subsequently, it was exposed to a gentle nitrogen flow to dry completely. The final residue was reconstituted in $150 \mu \mathrm{L}$ of the initial composition of mobile phase $\left(\mathrm{MeCN}: \mathrm{H}_{2} \mathrm{O} ; 25: 75 \mathrm{v} / \mathrm{v}\right.$ both containing $0.01 \%$ and $0.4 \%$ of FA for DAD and MS/MS, respectively). After filtration by PTFE filter, samples were injected in the UHPLC-MS/MS and/or DAD systems. Taking into account the steps involved in the sample treatment, sample throughput was approximately 15 samples per hour, with a preconcentration factor of 26.7 .

\section{Results and discussion}

\subsection{Optimization of UHPLC-DAD conditions}

The separation of the MCs and NOD was first performed by UHPLC-DAD. For this purpose different chromatographic columns were tested, ZorbaxC18 Eclipse Plus RRHD, Kinetex Biphenyl Core-Shell and Luna Omega polar C18, using water (solvent A) and MeCN (solvent B) as mobile phase and the following elution program: $0 \mathrm{~min}, 10 \% \mathrm{~B} ; 1 \mathrm{~min}, 10 \% \mathrm{~B} ; 2 \mathrm{~min}, 20 \%$ B; 4.5 min, 40\% B; 8.5min, 95\% B; 10 min, 95\% B, 13 min, 10\% B; 15 min,10\% B. Other separation parameters were a flow rate of $0.4 \mathrm{~mL} \mathrm{~min}^{-1}$, column temperature $50^{\circ} \mathrm{C}$ and injection volume $10 \mu \mathrm{L}$. Also, a Kinetex HILIC column was tested under a different gradient elution program (1 min, 80\% B; 2 min, 70\% B; 4.5 min, 60\% B; 10 min, 5\% B; 11 min, 5\% B, 14 min, $80 \%$ B, 16 min, 80\% B); while other separation parameters were the same. The Biphenyl CoreShell and HILIC columns did not provide any separation. Zorbax C18 Eclipse Plus RRHD and Luna Omega polar C18 showed a similar behavior but slightly higher resolution when Zorbax C18 was checked selecting this column to continue the optimization (Supplementary Data, Fig. SD1). Next, different mobile phase compositions were tested such as $\mathrm{H}_{2} \mathrm{O} / \mathrm{MeOH}$, $\mathrm{H}_{2} \mathrm{O} /\left(\mathrm{MeCN}: \mathrm{MeOH}\right.$ 25:75 v/v), $\mathrm{H}_{2} \mathrm{O} /\left(\mathrm{MeCN}: \mathrm{MeOH}\right.$ 50:50v/v), and $\mathrm{H}_{2} \mathrm{O} /(\mathrm{MeCN}: \mathrm{MeOH}$, $75: 25 \mathrm{v} / \mathrm{v}$ ), but they were discarded because either resolution or peak shapes were not satisfactory. Therefore, $\mathrm{H}_{2} \mathrm{O} / \mathrm{MeCN}$ was selected as it gave the best compromise between 
resolution, peak shape and analysis time. In the next step, the addition of HAc and FA at $0.1 \%$, in water and $\mathrm{MeCN}$ was assayed. Satisfactory sensitivity and baseline resolution for most of the analytes was obtained using $\mathrm{H}_{2} \mathrm{O} / \mathrm{MeCN}$ containing both $0.1 \%$ FA. Then, different amounts of FA $(0.1-0.01 \%(\mathrm{v} / \mathrm{v}))$ were checked. $0.01 \%$ of FA gave the best results in terms of resolution and baseline drift (Supplementary Data, Fig. SD2). In the next step, different flow rates (0.3 to 0.5 $\left.\mathrm{mL} \mathrm{min}^{-1}\right)$ and subsequently, various column temperatures $\left(25\right.$ to $\left.50^{\circ} \mathrm{C}\right)$ were investigated. Flow rates of $0.3 \mathrm{~mL} \mathrm{~min}^{-1}$ led to longer retention times and $0.5 \mathrm{~mL} \mathrm{~min}^{-1}$ resulted in poorer resolution for most analytes, therefore, $0.4 \mathrm{~mL} \mathrm{~min}^{-1}$ was selected as the best compromise between analysis time and resolution. On the other hand, no significant differences in the total separation time (about $7 \mathrm{~min}$ ) were observed in the temperature range studied. Therefore, separation was carried out at $25{ }^{\circ} \mathrm{C}$ which might extend the column life. Under the optimized conditions, the studied cyanotoxins were identified. Finally, different injection volumes were checked (5, 10 and 20 $\mu \mathrm{L}$ ). When the injection volume was increased, sensitivity was improved without losing peak resolution. Therefore, a volume of $20 \mu \mathrm{L}$ (full loop injection) was selected for the next steps.

\subsection{Optimization of UHPLC-MS/MS conditions}

A UHPLC-MS/MS method was developed in order to improve sensitivity and selectivity in real samples. For this purpose, the previously optimized chromatographic conditions were tested. In order to increase the sensitivity the amount of formic acid was tested to try to improve the ionization of the analytes. The FA amounts tested were $0.05 \%, 0.1 \%, 0.2 \%, 0.3 \%, 0.4 \%$ and $0.5 \%(\mathrm{v} / \mathrm{v})$ in water and $\mathrm{MeCN}$. Concentrations of FA up to $0.4 \%(\mathrm{v} / \mathrm{v})$ resulted in higher sensitivity and better peak shapes. Therefore, water and MeCN containing $0.4 \%$ (v/v) of FA was chosen as the best mobile phase (Fig.SD3).

Then optimization of ESI(+) and MRM parameters was performed. First of all, individual standard solutions of $750 \mu \mathrm{g} \mathrm{L}^{-1}$ for MC-LW, $500 \mu \mathrm{g} \mathrm{L}^{-1}$ for MC-RR, MC-YR, MC-LF, MC$\mathrm{LY}$, and MC-LA and $250 \mu \mathrm{g} \mathrm{L}{ }^{-1}$ for MC-LR, MC-WR, and NOD in water/MeCN 20:80(v/v), containing $0.4 \%$ of FA were prepared and subsequently infused directly into the mass spectrometer using ESI positive mode. Protonated molecular species $\left([\mathrm{M}+\mathrm{H}]^{+2}\right.$ for $\mathrm{MC}-\mathrm{RR}$ and $[\mathrm{M}+\mathrm{H}]^{+1}$ for the rest) were selected as precursor ions. The toxins studied had a common fragment at $m / z 135$, as the most abundant product ion. This is related to fragmentation of methoxy group 
of Adda amino acid. This highly intense product ion (Q) was used for quantification, while the second with higher abundance was selected for identification. In addition, other parameters related to MRM conditions such as declustering potential (DP), entrance potential (EP), collision cell entrance potential (CEP), collision gas (CAD), collision energy (CE) and collision exit potential (CXP) of the two selected transitions were investigated. The results are given in Table 1. To ensure at least 10 points per peak, a target scan time for each transition of $0.6 \mathrm{~s}$ was selected. Then, ionization source parameters were optimized using the previously established chromatographic conditions for solutions containing $100 \mu \mathrm{g} \mathrm{L}^{-1}$ of MC-RR and $250 \mu \mathrm{g} \mathrm{L}^{-1}$ for the other compounds studied. Each sample was injected three times and subsequently average intensities were investigated. For this purpose, source temperature, TEM $\left(300,350,400,450{ }^{\circ} \mathrm{C}\right)$, ion spray voltage, IS (4500, 4750, 5000, 5250 V), collisionally activated dissociation, CAD (5, 10, 15 psi), and curtain gas (nitrogen), CUR (25, 30, 35 psi) were studied (Fig.2). The best sensitivity was attained at TEM of $400{ }^{\circ} \mathrm{C}$, IS of $4750 \mathrm{~V}, \mathrm{CAD}$ of $15 \mathrm{psi}$, and CUR of 30 psi. Both GS1 and GS2 parameters were fixed at 50 psi (344.7 kPa).

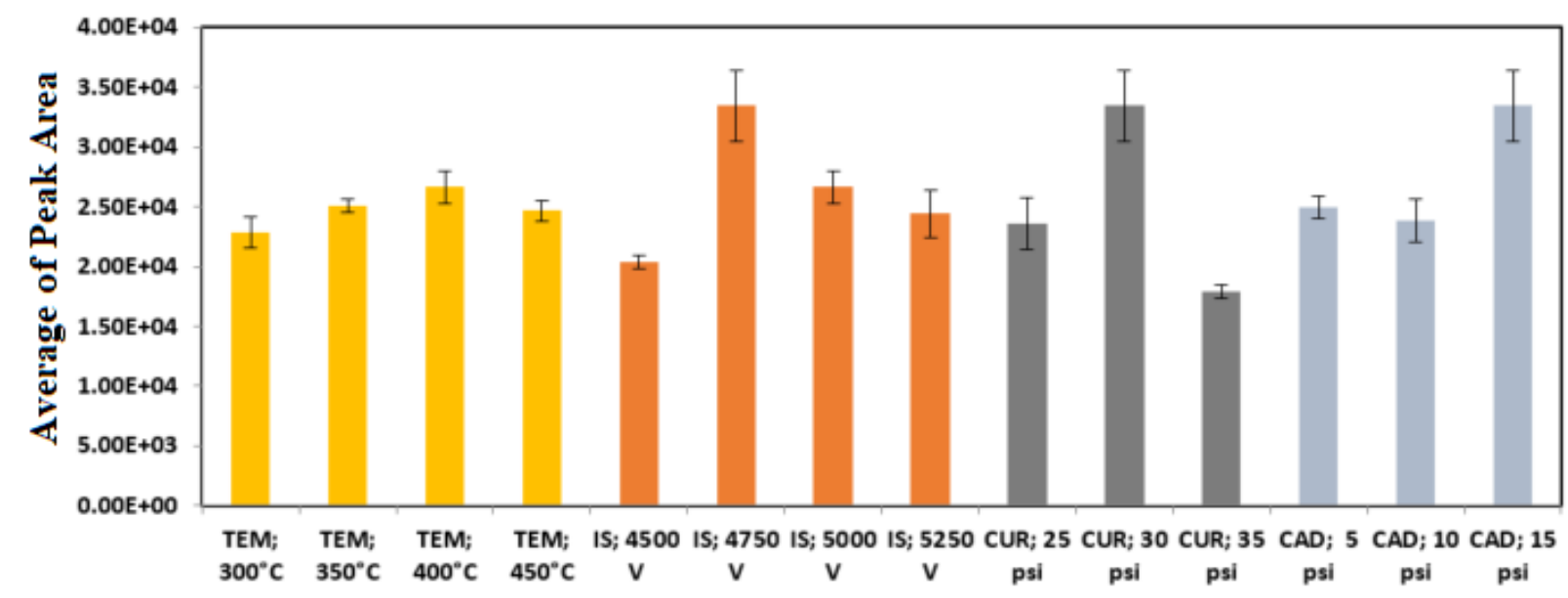

Fig. 2. Optimization of ESI (+) conditions (temperature of ion source (TEM); ion spray voltage (IS); curtain gas pressure (CUR); collision gas pressure (CAD), ( $n=3)\left(100 \mu \mathrm{g} \mathrm{L}^{-1}\right.$ for MC-RR, $250 \mu \mathrm{g} \mathrm{L}^{-1}$ for the rest of compounds). Error bars represent the standard error $(n=3)$. 


\subsection{Optimization of sample treatment procedure}

The high salinity of the water samples under study and the polarity of the toxins induced us to apply a salting-out assisted liquid-liquid extraction for the isolation and preconcentration of the analytes. This study was performed using UHPLC-UV.

To obtain satisfactory extraction efficiencies for the analytes studied, several parameters affecting the SALLE procedure such as sample $\mathrm{pH}$, type and volume of extraction solvent, type and amount of salting-out agent $\left(\mathrm{NaCl}, \mathrm{MgSO}_{4},\left(\mathrm{NH}_{4}\right)_{2} \mathrm{SO}_{4}\right)$ were investigated using $4 \mathrm{~mL}$ of water spiked at $20 \mu \mathrm{g} \mathrm{L}^{-1}$ of each analyte. Recoveries were calculated by comparing peak areas of samples spiked before the SALLE procedure with peak areas of samples spiked after the SALLE procedure. All the experiments were carried out in triplicate $(n=3)$.

Results given as average recoveries for all toxins versus involved parameters are shown in Fig.3.

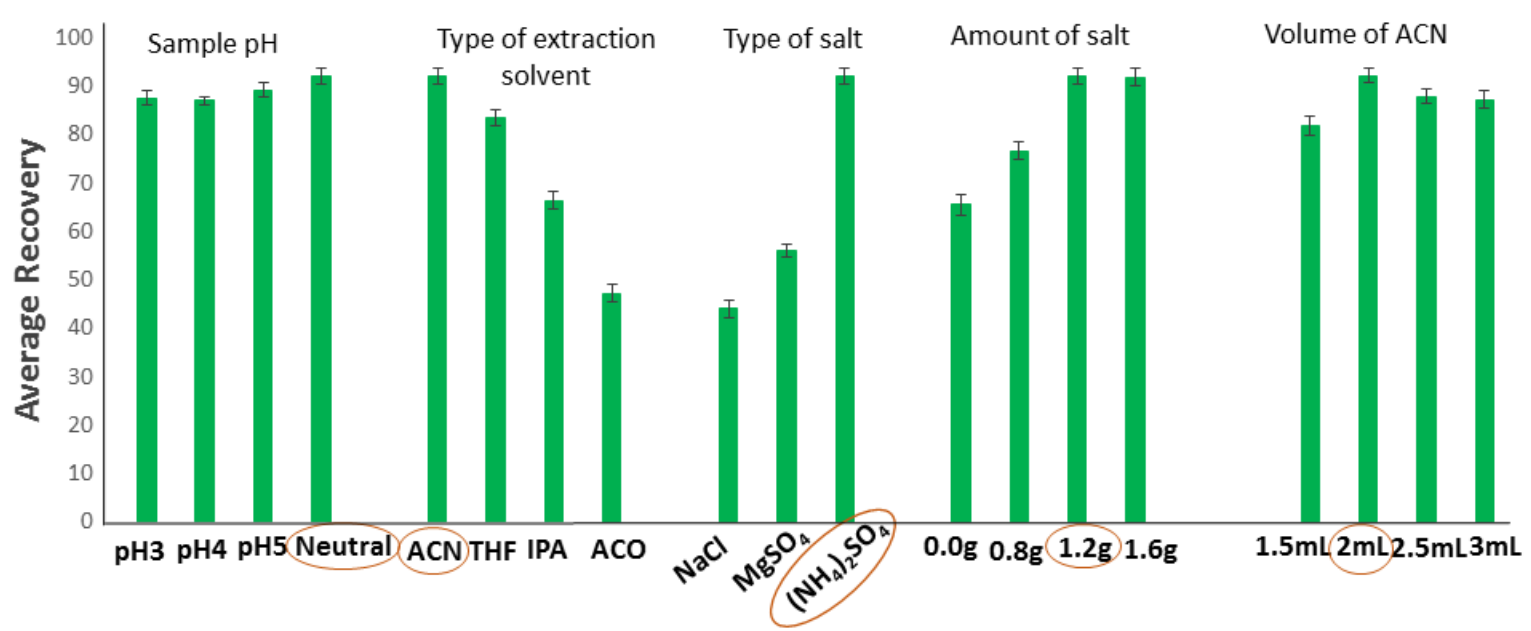

Fig. 3. Optimization of the main parameters involved in extraction of cyanotoxins by SALLE (pH, types of extraction solvent and salt, and extraction solvent volume). Error bars represent the standard error $(n=3)$.

As for the $\mathrm{pH}$ effect, it can be mentioned that MC-LR has three $\mathrm{pK}_{\mathrm{a}}$ values, which are related to two ionizable carboxylic groups and one ionizable amine group. These values are 2.09, 2.19, and 12.48 [35]; therefore, it may be expected that the best extraction occurs at acidic $\mathrm{pH}$ values where the compound is neutral. $\mathrm{p} K a$ values for the other compounds are 3.03 and 13.65 for MCRR, MC-WR, MC-YR, 3.39 and 13.65 for NOD and 3.03 for MC-LF, MC-LW, MC-LA, MCLY, calculated by using Advanced Chemistry Development software V11.02 (ACD/Labs, 
Toronto, Ontario, Canada) [36]. Therefore, in the current study, media ranging from acidic to neutral were studied using hydrochloric acid. Main extraction parameters were fixed at $2 \mathrm{~mL}$ of organic solvent and $1.6 \mathrm{~g}$ of $\left(\mathrm{NH}_{4}\right)_{2} \mathrm{SO}_{4}$. In our case, $\mathrm{pH}$ values of $3,4,5$ and 7 gave good extraction efficiencies showing that the influence of $\mathrm{pH}$ is negligible. However, the neutral medium provided maximum extraction efficiency (average recoveries higher than 93\%) (Fig.3). Therefore, other optimization processes were carried out in neutral medium. To study the kind of extraction agent, five common organic solvents named $\mathrm{MeCN}, \mathrm{MeOH}$, IPA, THF and ACO were tested. Unfortunately, the high water-miscibility of $\mathrm{MeOH}$, even in a salty medium, limited the application of SALLE to the target cyanotoxins. In practice, MeCN, IPA, THF and ACO showed good phase partition in the salt-induced extraction. However, extraction performance with $\mathrm{MeCN}$ was high for most compounds. Therefore, $\mathrm{MeCN}$ was used throughout the study (Fig.3). In the next step, the salting-out effect of three salts including $\mathrm{MgSO}_{4},\left(\mathrm{NH}_{4}\right)_{2} \mathrm{SO}_{4}$ and $\mathrm{NaCl}$ were evaluated using $1.6 \mathrm{~g}$ and keeping the other parameters constant. Phase separation was successfully achieved in all cases. However, $\mathrm{NaCl}$ showed the lowest extraction efficiency (below 40\%), especially for the five most hydrophilic compounds (MC-RR, NOD, MC-YR, MC$\mathrm{LR}$, and MC-WR). Also, $\mathrm{MgSO}_{4}$ resulted in extraction efficiencies that ranged from $40 \%$ to $70 \%$ for all compounds (average recoveries near to 55\%). The solvation heat produced when dissolving $\mathrm{MgSO}_{4}$ could be the cause of lower recoveries. So, $\left(\mathrm{NH}_{4}\right)_{2} \mathrm{SO}_{4}$ was selected as the best salting-out agent with average recoveries close to $90 \%$ (Fig.3).

Then, different amounts of $\left(\mathrm{NH}_{4}\right)_{2} \mathrm{SO}_{4}(0.8,1.2,1.6$ and $2.0 \mathrm{~g})$ were checked. When $0.8 \mathrm{~g}$ $\left(\mathrm{NH}_{4}\right)_{2} \mathrm{SO}_{4}$ was tested, collection of $1.5 \mathrm{~mL} \mathrm{MeCN}$ was relatively difficult. An optimum value of $1.2 \mathrm{~g}$ with recoveries of higher than $77.0 \%$ except for MC-RR and NOD was established for further study.

Finally, for optimization of the extraction volume, values of 1.5, 2.0, 2.5, and $3.0 \mathrm{~mL}$ of $\mathrm{MeCN}$ were investigated. As can be observed in Fig.3, $1.5 \mathrm{~mL}$ of $\mathrm{MeCN}$ led to low extraction efficiencies ( $<85 \%)$ while $2.0 \mathrm{~mL}$ of $\mathrm{MeCN}$ provided the best recoveries. Therefore, $2.0 \mathrm{~mL}$ of $\mathrm{MeCN}$ was chosen for future experiments. 


\subsection{Method validation}

To calculate the validation parameters for the two analytical methods, salted water Type B from the saline marsh was used as relevant matrix material.

\subsubsection{Matrix-matched calibration curves and figures of merit}

Calibration curves were built at different spiked concentration levels. For SALLE-UHPLC-DAD method, the concentrations were 5.0, 10.0, 20.0, 30.0, 50.0, and $75.0 \mu \mathrm{g} \mathrm{L}^{-1}$ for all compounds; In the case of SALLE-UHPLC-MS/MS 0.1, 0.25, 0.5, 1.0, 5.0, and $10.0 \mu \mathrm{g} \mathrm{L}^{-1}$ for MC-RR, MCLA, MC-LF, and NOD; 0.3, 0.625, 1.25, 2.5, 5.0, 12.5, and $25.0 \mu \mathrm{g} \mathrm{L}^{-1}$ for MC-YR, MC-LR, MC-WR, MC-LY, and MC-LW were the studied concentrations. Analyses of blank samples of the saline waters indicated no evidence of the aforementioned analytes. Two samples were prepared at each concentration level, following the sample treatment procedure, and then injected twice into the UHPLC-DAD and UHPLC-MS/MS instruments. LODs and LOQs were calculated on the basis of signal-to-noise ratios equal to 3 and 10, respectively. As can be observed in Table 2, LOD and LOQ values obtained with SALLE-UHPLC-DAD were arranged in the range of 1.0 to $3.4 \mu \mathrm{g} \mathrm{L} \mathrm{L}^{-1}$ and 3.4 to $11.5 \mu \mathrm{g} \mathrm{L}{ }^{-1}$, respectively. By SALLE-UHPLC-MS/MS, LOD and LOQ values varied in the range of 0.03 to $0.07 \mu \mathrm{g} \mathrm{L}^{-1}$ and 0.07 to $0.2 \mu \mathrm{g} \mathrm{L}^{-1}$ respectively (Table 3), between 33 to 48 times lower.

Table 2. Characteristics of matrix-matched calibration curves of SALLE-UHPLC-DAD method for cyanotoxin determination in saline water (Type $\mathrm{B}^{*}$ ).

\begin{tabular}{|l|c|c|c|c|}
\hline \multirow{2}{*}{ Analyte } & \multicolumn{4}{|c|}{ SALLE-UHPLC-DAD } \\
\cline { 2 - 5 } & $\mathbf{L O D}\left(\boldsymbol{\mu g ~ \mathbf { ~ L } ^ { - 1 } )}\right.$ & $\mathbf{L O Q}\left(\boldsymbol{\mu g} \mathbf{~ L}^{-1}\right)$ & Linear dynamic range $\left(\boldsymbol{\mu \mathbf { g ~ L } ^ { - 1 } )}\right.$ & $\mathbf{R}^{2}$ \\
\hline \multirow{2}{*}{ MC-RR } & 2.4 & 8.0 & $8.0-75.0$ & 0.9976 \\
\hline NOD & 1.2 & 4.0 & $4.0-75.0$ & 0.9961 \\
\hline MC-YR & 1.0 & 3.4 & $3.4-75.0$ & 0.9951 \\
\hline MC-LR & 1.2 & 4.0 & $4.0-75.0$ & 0.9944 \\
\hline MC-WR & 1.0 & 3.4 & $3.4-75.0$ & 0.9921 \\
\hline MC-LA & 3.4 & 11.5 & $11.5-75.0$ & 0.9947 \\
\hline MC-LY & 1.5 & 5.0 & $5.0-75.0$ & 0.9938 \\
\hline MC-LW & 3.0 & 10.0 & $10.0-75.0$ & 0.9902 \\
\hline MC-LF & 3.0 & 10.0 & $10.0-75.0$ & 0.9904 \\
\hline
\end{tabular}

Type B*: Saline water with $21^{\circ}$ Baumé 
Table 3. Characteristics of matrix-matched calibration curves of SALLE-UHPLC-MS/MS method for cyanotoxin determination in saline water (Type $\mathrm{B}^{*}$ ).

\begin{tabular}{|l|c|c|c|c|c|}
\hline \multirow{2}{*}{ Analyte } & \multicolumn{5}{|c|}{ SALLE-UHPLC MS/MS } \\
\cline { 2 - 6 } MC-RR & LOD $\left(\boldsymbol{\mu g} \mathbf{L}^{-\mathbf{1}}\right)$ & $\mathbf{L O Q}\left(\boldsymbol{\mu g} \mathbf{L}^{-\mathbf{1}}\right)$ & Linear dynamic range $\left(\boldsymbol{\mu g} \mathbf{L}^{-\mathbf{1}}\right)$ & $\mathbf{R}^{\mathbf{2}}$ & $\mathbf{M E \%}$ \\
\hline NOD & 0.07 & 0.22 & $0.22-10.0$ & 0.9915 & -80.7 \\
\hline MC-YR & 0.02 & 0.07 & $0.07-10.0$ & 0.9964 & -79.0 \\
\hline MC-LR & 0.11 & 0.35 & $0.36-25.0$ & 0.9932 & -22.5 \\
\hline MC-WR & 0.04 & 0.15 & $0.12-25.0$ & 0.9909 & -10.5 \\
\hline MC-LA & 0.03 & 0.09 & $0.15-25.0$ & 0.9923 & -11.7 \\
\hline MC-LY & 0.11 & 0.36 & $0.09-10.0$ & 0.9937 & -32.8 \\
\hline MC-LW & 0.04 & 0.15 & $0.36-12.5$ & 0.9889 & 32.5 \\
\hline MC-LF & 0.03 & 0.09 & $0.15-25.0$ & 0.9950 & -31.0 \\
\hline
\end{tabular}

Type B*: Saline water with $21^{\circ}$ Baumé

\subsubsection{Matrix effect}

Matrix effect (ME\%) is the effect produced on the analytical signal by endogenous compounds in the sample. It can be obtained by comparing the slopes of matrix-matched calibration curves (obtained by adding increasing concentrations of toxins to an extract of a blank sample) with the slopes of external standard calibration curves, both obtained with the same final concentration levels. The following equation was used [37]:

$$
\operatorname{ME}(\%)=\left(\left(\frac{\text { slope of matrix matched calibration curve }}{\text { slope of external calibration curve }}\right)-1\right) \times 100
$$

As shown in Table 3, most of the \% ME values are lower than $33.0 \%$, except for the most polar analytes, MC-RR and NOD. Consequently, the efficiency of the proposed methodology for the determination of the target toxins is high but polar compounds exhibit a high matrix effect and subsequently low extraction recovery in highly saline matrices. 


\subsubsection{Precision assessment}

Repeatability (intra-day) and intermediate precision (inter-day) for both SALLE-UHPLC-DAD and SALLE-UHPLC-MS/MS methods were studied at two different levels as indicated in Table SD1. Repeatability was assessed on the same day by means of repetitive application of the SALLE procedure to three samples at each concentration level, and each one was injected twice $(n=6)$. Intermediate precision was assessed for three consecutive days (in one day: three samples were prepared and each one was injected twice; while in two other days one sample was prepared and injected twice, $\mathrm{n}=10$ ). The parameters were calculated as $\%$ RSD of the peak areas. RSD\% values are lower than 14.5 and $11.2 \%$ for inter and intra-day precision studied by SALLE-UHPLC-DAD and 16.0 and $15.4 \%$ for inter and intra-day precision by SALLE-UHPLCMS/MS methodology.

\subsubsection{Recovery assessment}

In order to investigate the trueness of the proposed methodologies, a recovery study was carried out in water samples obtained from two storage tanks with different salinity (Type A $19^{\circ}$ Baume, Type B $21^{\circ}$ Baume), located in the continental salt marsh. For this purpose, two samples of each saline water type were spiked at the same concentration levels previously used in the precision study. After pre-treatment of saline matrices, each one was analyzed by duplicate. Also, matrix blanks were analyzed following the same methodology, indicating the absence of the studied toxins prior to our deliberate spiking. Afterwards, recoveries were calculated by comparing peak areas of samples spiked before the SALLE procedure with peak areas of samples spiked after the SALLE procedure. The results are given in Tables 4 and 5. SALLE-UHPLC-DAD method was applied only to water Type B with extraction recoveries higher than $77.3 \%$ (with \%RSD <12.4 for $n=4)$, except for the most polar toxins, named MC-RR and NOD, that have recovery values ranging from 58.5 to $73.1 \%$. For SALLE-UHPLC-MS/MS procedure the recoveries obtained varied between 71.6 to $99.7 \%$ with \%RSD $<13.0$ for $n=4$, while the recovery values for MC-RR and NOD are included between 53.2 to $68.7 \%$. From these results it can be conclude that matrixmatched calibrations should be used to analyze the toxins in these waters, and no differences were observed between the two types of water analyzed. 
Table 4. Ranges of recoveries and \%RSD for cyanotoxin determination in saline water by SALLE-UHPLC-DAD method $(n=4)$.

\begin{tabular}{|l|l|c|c|c|c|}
\hline \multirow{2}{*}{ Analyte } & \multirow{2}{*}{\begin{tabular}{l} 
Sample \\
\cline { 3 - 6 }
\end{tabular}} & & \multicolumn{4}{|c|}{ SALLE-UHPLC-DAD } \\
\cline { 3 - 6 } & Level 1A & \multicolumn{3}{c|}{ Level 2A } \\
\cline { 3 - 6 } MC-RR & \multirow{2}{*}{ Type B } & 58.5 & 5.8 & 61.9 & 12.4 \\
\hline MC-YR & Type B & 67.8 & 9.2 & 73.1 & 8.1 \\
\hline MC-LR & Type B & 77.3 & 5.2 & 86.7 & 7.0 \\
\hline MC-WR & Type B & 91.0 & 6.8 & 91.8 & 6.5 \\
\hline MC-LA & Type B & 91.4 & 6.7 & 93.8 & 6.2 \\
\hline MC-LY & Type B & 93.4 & 6.5 & 91.1 & 6.4 \\
\hline MC-LW & Type B & 94.1 & 6.3 & 94.3 & 6.2 \\
\hline MC-LF & Type B & 86.5 & 6.5 & 87.7 & 7.3 \\
\hline
\end{tabular}

Level 1A: $15.0 \mu \mathrm{g} \mathrm{L}^{-1}$ MC-RR, YR, LR, WR, LA, LY, LW, LF, and NOD Level 2A: $30.0 \mu \mathrm{g} \mathrm{L}^{-1}$ MC-RR, YR, LR, WR, LA, LY, LW, LF, and NOD Type B: Saline water with $21^{\circ}$ Baumé

Fig. 4 displays chromatograms for blank saline water (Type B) and spiked at the level of $15 \mu \mathrm{g}$ $\mathrm{L}^{-1}$ for all toxins under study, obtained by the SALLE-UHPLC-DAD method. Fig. 5 shows the extracted ion chromatogram for saline water (Type B) spiked at $0.5 \mu \mathrm{g} \mathrm{L}^{-1}$ (MC-RR, MC-LA, MCLF, and NOD) and $1.25 \mu \mathrm{g} \mathrm{L}^{-1}$ (MC-YR, MC-LR, MC-WR, MC-LY, and MC-LW) by SALLE-UHPLC-MS/MS methodology. The blanks recorded by both methodologies highlight the absence of the toxins above the LODs calculated. 


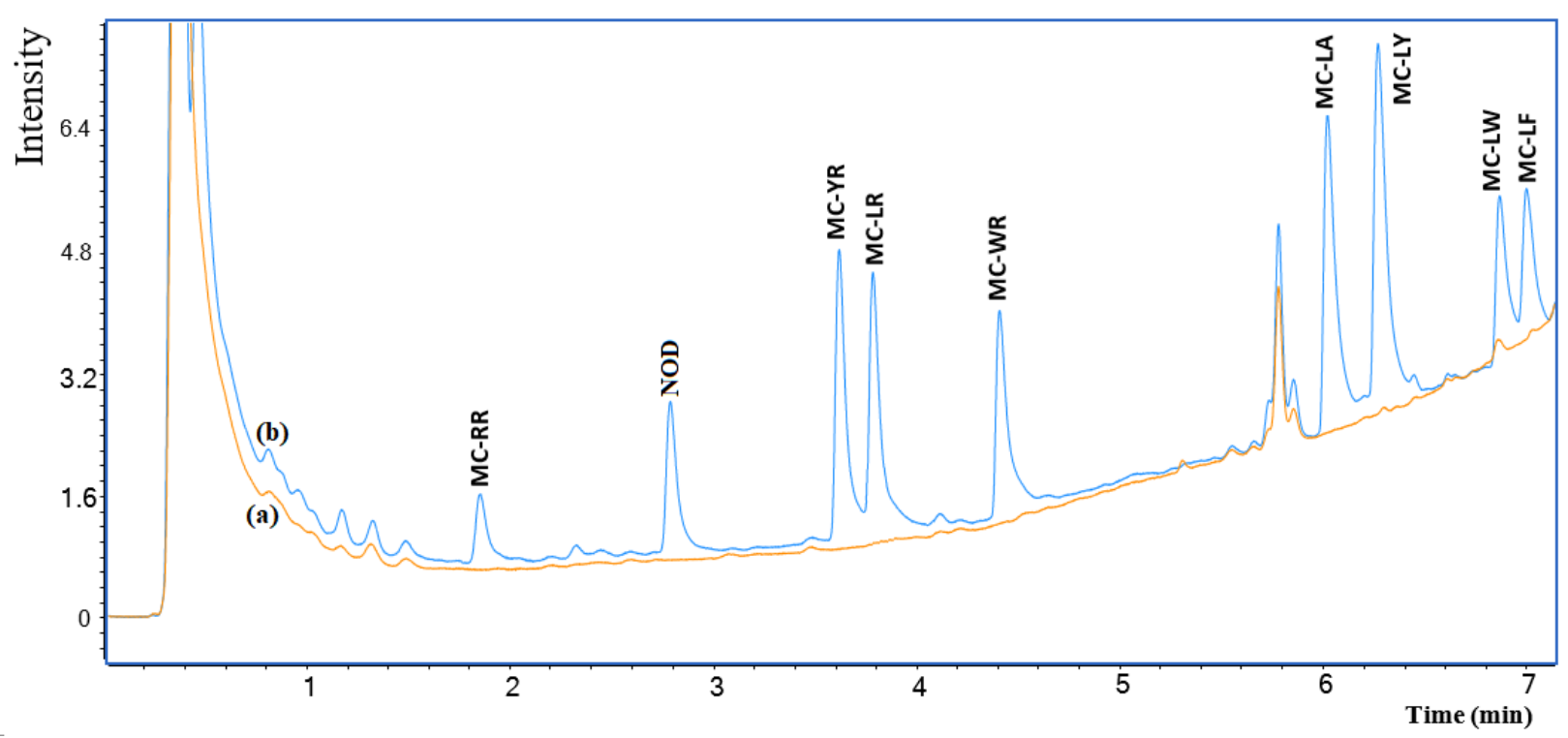

Fig. 4. Chromatograms obtained by the SALLE-UHPLC-DAD method developed showing (a) a blank sample and (b) a spiked saline water sample at $15 \mu \mathrm{g} \mathrm{L}^{-1}$ level.

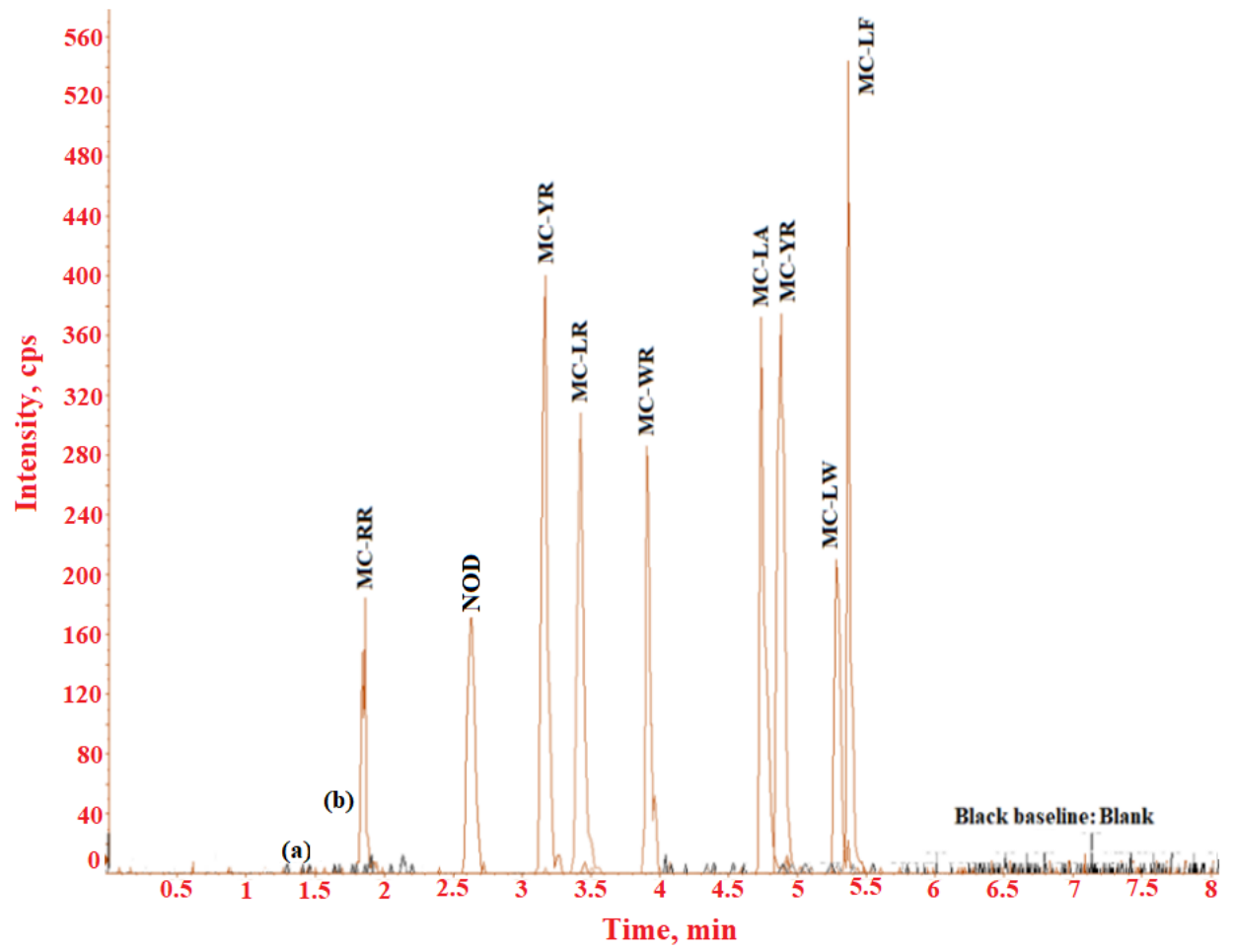

Fig. 5. Chromatograms obtained by the SALLE-UHPLC-MS/MS method developed showing (a) a blank and (b) a spiked saline water sample at $0.5 \mu \mathrm{g} \mathrm{L}^{-1}$ (MC-RR, MC-LA, MC-LF, and NOD) and $1 \mu \mathrm{g} \mathrm{L}^{-1}$ (MC-YR, MC-LR, MC-WR, MC-LY, and MC-LW) levels. 


\section{Conclusions}

The increasing demand of alternative foods with added properties is leading to the consumption of new products such as microalgae and cyanobacteria. However, the latter can produce highly toxic secondary metabolites. This demand is therefore accompanied by the need to have rapid and simple analytical methodologies that allow us to obtain reliable information in a short time.

The majority of existing methods use liquid chromatography as the analytical technique and therefore our principal contribution is found in the sample treatment applied as well as a rigorous validation of the methods utilising both detectors, DAD and MS/MS.

The choice to use SALLE was made considering firstly the type of matrix that we needed to analyse: water from hypersaline microalgae colonies never explored before, and secondly the characteristics of the procedure in terms of simplicity, speed, availability, low cost and low environmental impact. All of these aspects are essential to any developed methodology given the fact that this is all part of a larger project which involves exploitation of the microalgaes produced through natural means in this salt marsh so quality and food safety protocols must be in place.

In the case of these samples, options other than SALLE have been unsuccessful up to now. Direct analysis of the water samples without any additional sample concentration or extraction step is not possible given the high saline content of the samples which leads to high ion suppression.

Solid-Phase Extraction (SPE) is mainly applied as clean-up/enrichment procedure prior to final chromatographic analysis of cyanotoxins. In off-line configuration two new materials have been proposed recently for the analysis of MCs in environmental water and exhibited excellent extraction performance. However, the authors manufactured a sorbent material which for others might be difficult or impossible to obtain which makes it totally inappropriate for a routine task. The proposed method based on SALLE-UHPLC-DAD is very useful for fast and cheap screening analysis. However, the LODs obtained for the toxins ranging from 1.0 to $3.4 \mu \mathrm{g} \mathrm{L}^{-1}$ may not be sufficiently low given the toxicity of these compounds at very low concentrations. The use of a triple quadrupole mass spectrometer as detector allows reducing the LODs between a $30 \%$ and $50 \%$ with values ranging from 0.02 and $0.11 \mu \mathrm{g} \mathrm{L} \mathrm{L}^{-1}$. In addition, MS/MS detection is a more reliable confirmatory method. 
On the other hand, the high matrix effect and low extraction recovery for the two most polar compounds (MC-RR and NOD) can be somewhat compensated by the high sensitive of the MS/MS detection.

\section{Declaration of Competing of Interest}

The authors declare that they have no known competing financial interest on personal relationships that could have appeared to influence the work reported in this paper.

\section{Acknowledgment}

The authors gratefully acknowledge the financial support of the Spanish Ministry of Science, Innovation and Universities (Project Ref.: RTI2018-097043-B-I00). Maryam Hemmati thank Semnan University as well as Ministry of Science, Research, and Technology of Iran for endowment of the predoctoral fellowship. FJL is grateful for personal funding through the Special Research Program of the University of Granada. The authors gratefully acknowledge also Luciano Vílchez for the provision of the saline water samples analyzed in this study and John Ray for English revision. 


\section{References}

[1] JW Schopf, Microfossils of the Early Archean Apex chert: new evidence of the antiquity of ife, Science 260 (1993) 640-646.

[2] J. Meriluoto, L. Spoof, GA. Codd (Eds.), Handbook of cyanobacterial monitoring and cyanotoxin analysis, first ed., John Wiley \& Sons, Inc., Chichester, United Kingdom 2017.

[3] F. Haque, S. Banayan, J. Yee, Y. Wai Chiang, Extraction and applications of cyanotoxins and other cyanobacterial secondary metabolites, Chemosphere 183 (2017) 164-175. DOI: 10.1016/j.chemosphere.2017.05.106.

[4] H. Liang, W. Zhou, Y. Zhang, Q. Qiao, X. Zhang, Are fish fed with cyanobacteria safe, nutritious and delicious?. A laboratory study, Sci. Rep. 5 (2015) 15166.

[5] R. Kurmayer, K. Sivonen, A. Wilmotte, N. Salmaso (Eds.), Molecular tools for the detection and quantification of toxigenic cyanobacteria, John Wiley \& Sons, Inc., Chichester, United Kingdom 2017.

[6] L. Takser, N. Benachour, B. Husk, H. Cabana, D. Gris, Cyanotoxins at low doses induce apoptosis and inflammatory effects in murine brain cells: Potential implications for neurodegenerative diseases, Toxicol Rep, 3 (2016) 180-189.

[7] WHO, World Health Organisation Report. (2008). The World Health Report - Guideline for Drinking Water Quality: Third Edition. World Health Organisation, Geneva, Switzerland, 2008.

[8] WHO, World Health Organisation Report, (2003). Algae and Cyanobacteria in Fresh Water. Guidelines for Safe Recreational Water Environments. Volume 1: Coastal and Fresh Waters. Chapter 8 (2003) 136-158.

[9] D. Dietrich, S. Hoeger, Guidance values for microcystins in water and cyanobacterial supplement products (blue-green algal supplements): A reasonable or misguided approach?, Toxicol. Appl. Pharmacol. 203 (2005) 273-289.

[10] E. Testai, F.M. Buratti, E. Funari, M. Manganelli, S. Vichi, N. Arnich, R. Biré, V. Fessard, A. Sialehaamoa, Review and analysis of occurrence, exposure and toxicity of cyanobacteria toxins in food. EFSA supporting publication 2016:EN-998. 309 pp.

[11] PSM. Vesterkvist, JO Misiorek, LEM Spoof, DM Toivola, JAO Meriluoto, Comparative Cellular Toxicity of Hydrophilic and Hydrophobic Microcystins on Caco-2 Cells, Toxins 4 (2012) 1008-1023.

[12] H. Zhang, S. Yang, R.C. Beier, N. V. Beloglazova, H. Lei, X. Sun, Y. Ke, S. Zhang, Z. Wang, Simple, high efficiency detection of microcystins and nodularin-R in water by fluorescence polarization immunoassay, Anal. Chim. Acta. 992 (2017) 119-127.

[13] N.Tokodi, D. Drobac, G. Lazić, T. Petrović, Z. Marinović, J. Lujić, T. P Malešević, J. Meriluoto, Z. Svirčev, Screening of cyanobacterial cultures originating from different environments for cyanotoxicity and cyanotoxins, Toxicon 154 (2018) 1-6.

[14] L. Xie, HD Park, Determination of microcystins in fish tissues using HPLC with a rapid and efficient solid phase extraction, Aquaculture 271 (2007) 530-536.

[15] L Spoof, MR Neffling, J. Meriluoto, Fast separation of microcystins and nodularins on narrow-bore reversed-phase columns coupled to a conventional HPLC system, Toxicon 55 (2010) 954-964. 
[16] YM. Chen, TH. Lee, SJ. Lee, JZ. Lin, R. Huang, HN. Chou, Potential of a simple solidphase extraction method coupled to analytical and bioanalytical methods for an improved determination of microcystins in algal samples, J. Chromatogr. B, 844 (2006) 134-141.

[17] J. Chen, T. Yan, S. He, P. Zhao, X. Yan, Simultaneous determination of toxins in algae and water samples by high-performance liquid chromatography with triple quadrupole mass spectrometry, J. Sep. Sci. 35 (2012) 1094-1101.

[18] A. Mekebri, G.J. Blondina, D.B. Crane, Method validation of microcystins in water and tissue by enhanced liquid chromatography mass spectrometry, J. Chromatogr. A 1216 (2009) 3147-3155.

[19] G. Munoz, S.V. Duy, A. Roy-Lachapelle, B. Huskc, S. Sauvé, Analysis of individual and total microcystins in surface water by on-line preconcentration and desalting coupled to liquid chromatography tandem mass spectrometry, J. Chromatogr. A 1516 (2017) 9-20.

[20] A.D. Turner, J. Waacka, A. Lewisa, C. Edwardsb, L. Lawton, Development and singlelaboratory validation of a UHPLC-MS/MS method for quantitation of microcystins and nodularin in natural water, cyanobacteria, shellfish and algal supplement tablet powders, J. Chromatogr. B 1074-1075 (2018) 111-123.

[21] H. Pekar, E. Westerberg, O. Bruno, A. Lääne, K.M. Persson, L.F. Sundström, A.M. Thim, Fast, rugged and sensitive ultra high pressure liquid chromatography tandem mass spectrometry method for analysis of cyanotoxins in raw water and drinking water-First findings of anatoxins, cylindrospermopsins and microcystin variants in Swedish source waters and infiltration ponds, J. Chromatogr. A, 1429 (2016) 265-276.

[22] A. Roy-Lachapelle, M. Solliec, M.F. Bouchard, S. Sauvé, Detection of Cyanotoxins in Algae Dietary Supplements, Toxins 9 (2017) 76.

[23] J. Beri, K.I. Kirkwood, D.C. Muddiman, M.S. Bereman, A novel integrated strategy for the detection and quantification of the neurotoxin $\beta-\mathrm{N}$-methylamino-L-alanine in environmental samples, Anal. Bioanal. Chem. 410 (2018) 2597-2605.

[24] B. Zheng, H. Fu, J.P. Berry, B. McCord, A rapid method for separation and identification of microcystins using capillary electrophoresis and time-of-flight mass spectrometry, J. Chromatogr. A 1431 (2016) 205-214.

[25] A.M. Devasurendraa, D.S.W. Palagamaa, A. Rohanifara, D. Isailovica, J.R. Kirchhoffa, J.L. Anderson, Solid-phase extraction, quantification, and selective determination of microcystins in water with a gold-polypyrrole nanocomposite sorbent material, J. Chromatogr. A 1560 (2018) $1-9$.

[26] S.K. Zervou, C. Christophoridis, T. Kaloudis, T.M. Triantis, A. Hiskia, New SPE-LCMS/MS method for simultaneous determination of multi-class cyanobacterial and algal toxins, J. Hazard. Mater. 323 (2017) 56-66.

[27] W. Zhang, M. Lin, M. Wang, P. Tong, Q. Lu, L. Zhang, Magnetic porous $\beta$-cyclodextrin polymer for magnetic solid-phase extraction of microcystins from environmental water samples, J. Chromatogr. A, 1503 (2017) 1-11.

[28] Y. Shan, X. Shi, A. Dou, C. Zou, H. He, Q. Yang, S. Zhao, X. Lu, G. Xu, A fully automated system with on-line micro solid-phase extraction combined with capillary liquid chromatography-tandem mass spectrometry for high throughput analysis of microcystins and nodularin-R in tap water and lake water, J. Chromatogr. A, 1218 (2011) 1743-1748. 
[29] E. Beltrán, M. Ibáñez, J.V. Sancho, F. Hernández, Determination of six microcystins and nodularin in surface and drinking waters by on-line solid phase extraction-ultra high pressure liquid chromatography tandem mass spectrometry, J. Chromatogr. A, 1266 (2012) 61-68.

[30] O. Filippou, D. Bitas, V. Samanidou, Green approaches in sample preparation of bioanalytical samples prior to chromatographic analysis, J. Chromatogr. B, 1043 (2017) 44-62.

[31] R.E. Majors, Salting-out liquid-liquid extraction (SALLE), LCGC N. Am., 27 (2009) 526533.

[32]S. Cirés, MC Casero, A. Quesada, Toxicity at the edge of life: A review on cyanobacterial toxins from extreme environments, Mar. Drugs, 15, 233 (2017) 1-18.

[33] S. D. Varfolomeev, L. A. Wasserman, Microalgae as source of biofuel, food, fodder, and medicines, Appl. Biochem. Microbiol. 47 (2011) 789-806.

[34] M. Ruiz Alamino, Analysis of microcystins LR and RR in water samples from cultures of hypersaline microalgae, Thesis of Master, University of Granada, 2017, URI: http://hdl.handle.net/10481/48788.

[35] H. Yu, K.D. Clark, J.L. Anderson, Rapid and sensitive analysis of microcystins using ionic liquid-based in situ dispersive liquid-liquid microextraction, J. Chromatogr. A, 1406 (2015) 1018.

[36] https://scifinder.cas.org/ (accessed 29.03.19).

[37] B.K. Matuszewski, M.L. Constanzer, C.M. Chavez-Eng, Strategies for the assessment of matrix effect in quantitative bioanalytical methods based on HPLC-MS/MS, Anal. Chem. 75 (2003) 3019-3030. 
Supplementary data for

Monitoring of cyanotoxins in water from hypersaline microalgae colonies by ultra high

performance liquid chromatography with diode array and tandem mass spectrometry detection

following salting-out liquid-liquid extraction

Maryam Hemmati(1,2), Carmen Tejada-Casado(1), Francisco J. Lara (1), Ana M. García-

Campaña(1), Maryam Rajabi(2), Monsalud del Olmo-Iruela (1)* 

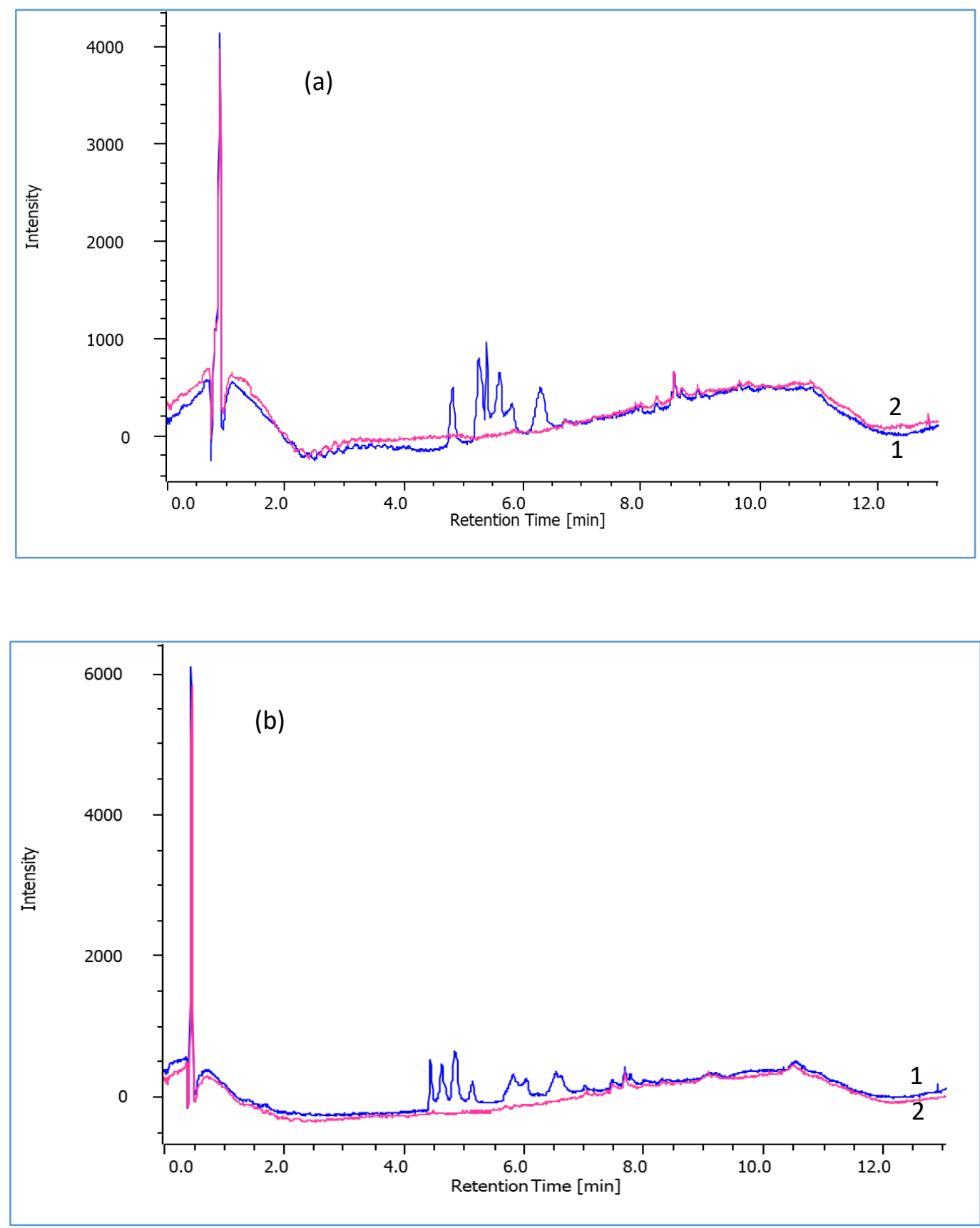

Fig. SD1(a and b): Optimization of column type. (a) Luna Omega polar C18; (b) ZorbaxC18; (mobile phases: water (solvent A) and $\mathrm{MeCN}$ (solvent B); column temperature $50^{\circ} \mathrm{C}$, flow rate $0.4 \mathrm{~mL} \mathrm{~min}^{-1}$ and $20 \mu \mathrm{L}$ of injection volume).(1) Standard chromatogram (2) Blank chromatogram. 

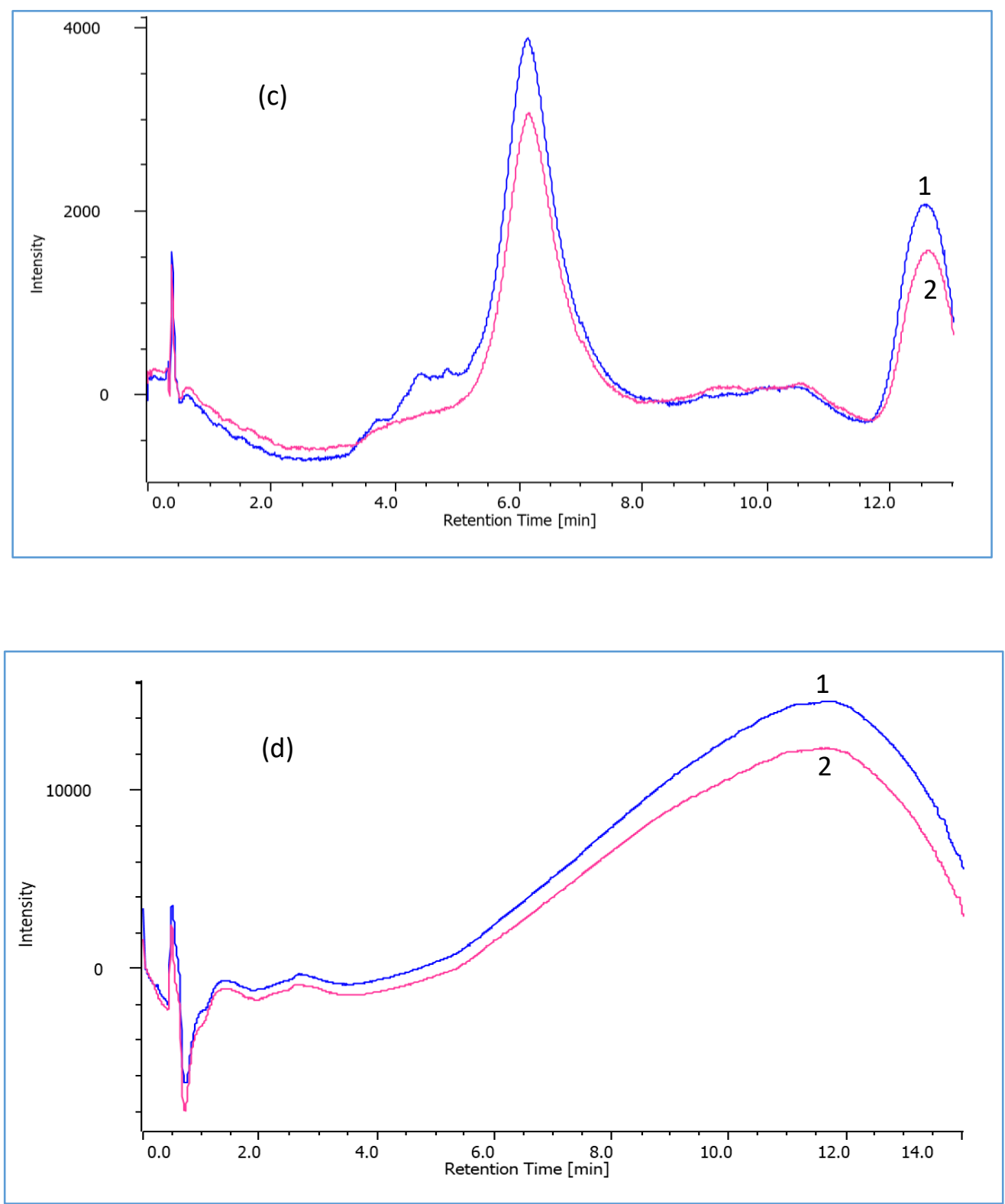

Fig. SD1 (c and d): Optimization of column type: (c) Kinetex Biphenyl Core-Shell; (d) Kinetex HILIC; (mobile phases: water (solvent A) and $\mathrm{MeCN}$ (solvent B); temperature $50^{\circ} \mathrm{C}$, flow rate $0.4 \mathrm{~mL} \mathrm{~min}^{-1}$ and $20 \mu \mathrm{L}$ of injection volume).(1) Standard chromatogram (2) Blank chromatogram. 


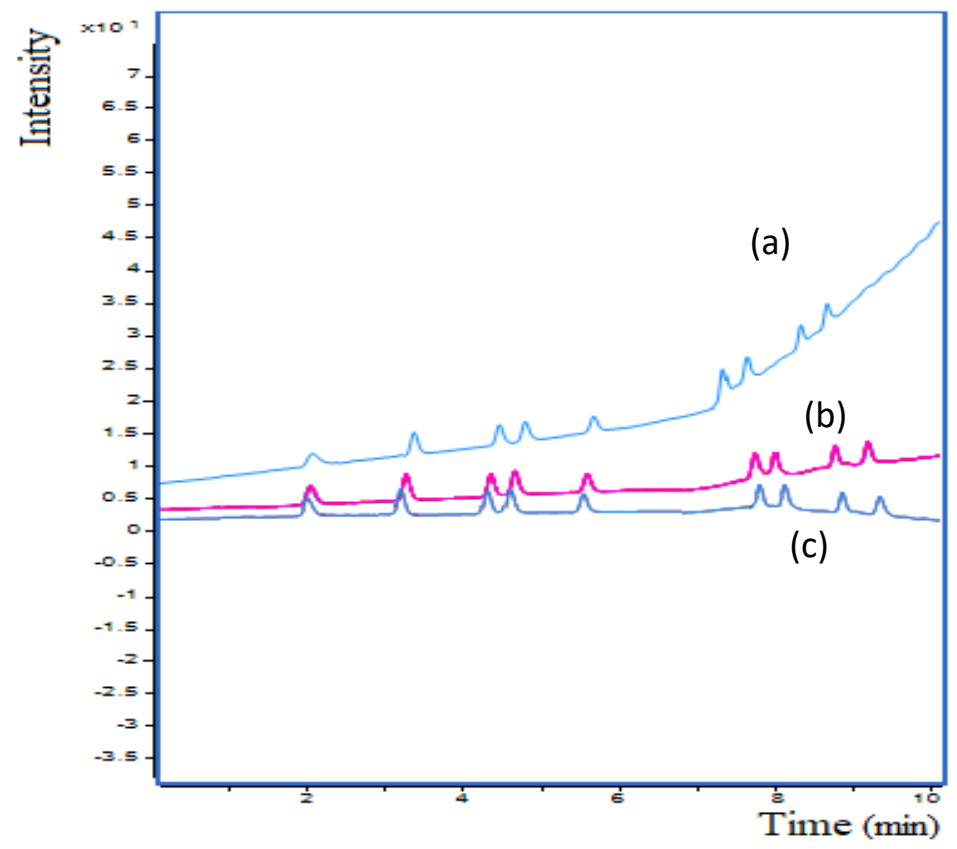

Fig. SD2(a-c): Optimization of \%FA in mobile phase (Water / MeCN): (a) 0.1\%; (b) $0.05 \%$; (c) $0.01 \%$; Zorbax C18 column with temperature $50^{\circ} \mathrm{C}$, flow rate $0.4 \mathrm{~mL} \mathrm{~min}^{-1}$ and $10 \mu \mathrm{L}$ of injection volume.

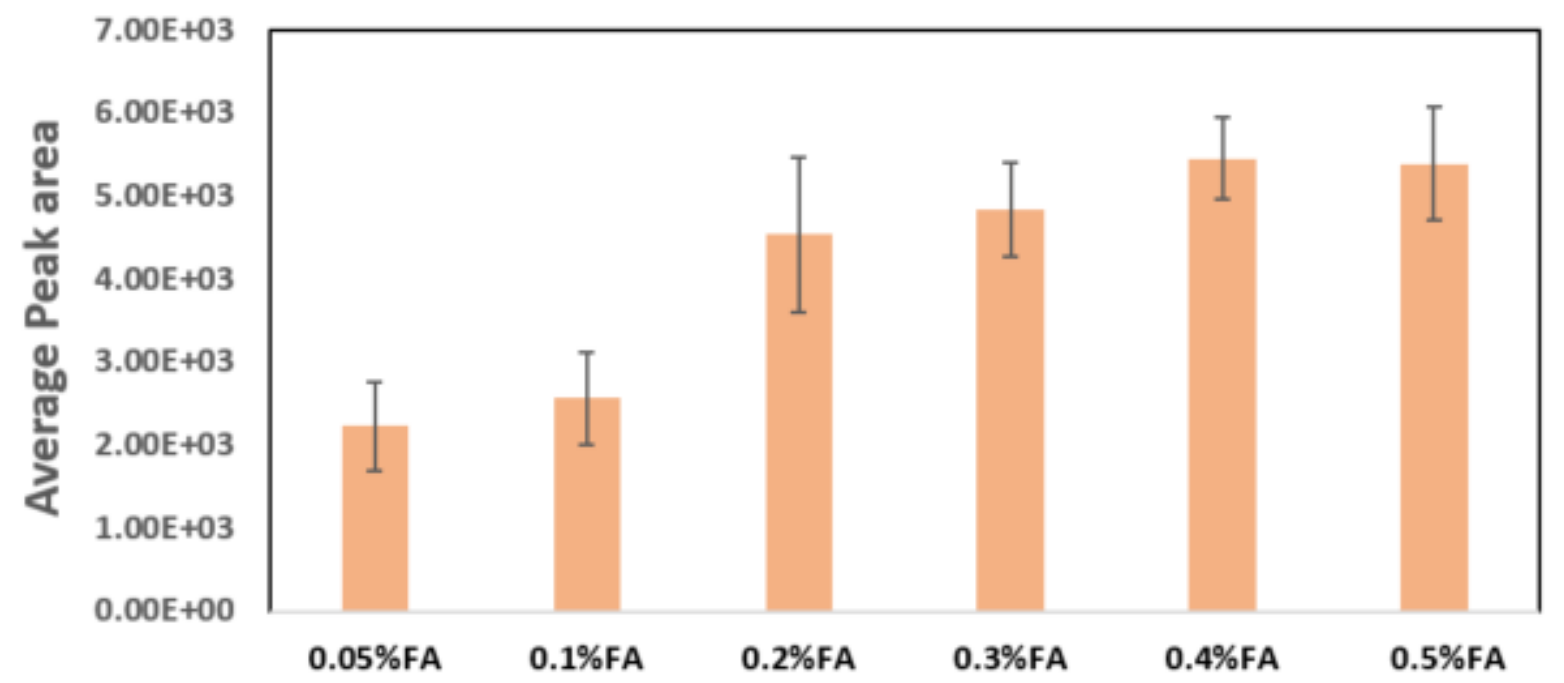

Fig. SD3: Optimization of the amount of \%FA in both MeCN/water for MS/MS-ESI(+); $(n=3$, injection volume $10 \mu \mathrm{L}$, concentration $50 \mu \mathrm{g} \mathrm{L}^{-1}$ ); Error bars represent standard deviation of three injections of the same sample. 
Table SD1. Repeatability and intermediate precision study for SALLE-UHPLC-DAD and SALLE-UHPLC MS/MS methods for cyanotoxin determination in saline water

\begin{tabular}{|c|c|c|c|c|c|c|c|c|}
\hline \multirow[b]{3}{*}{ Analyte } & \multicolumn{4}{|c|}{ SALLE-UHPLC-DAD } & \multicolumn{4}{|c|}{ SALLE-UHPLC MS/MS } \\
\hline & \multicolumn{2}{|l|}{ Level 1A } & \multicolumn{2}{|l|}{ Level 2A } & \multicolumn{2}{|l|}{ Level 1B } & \multicolumn{2}{|l|}{ Level 2B } \\
\hline & $\begin{array}{l}\text { Intra-day } \\
\text { RSD\% } \\
(\mathbf{n}=\mathbf{6})\end{array}$ & $\begin{array}{l}\text { Inter-day } \\
\text { RSD\% } \\
(\mathbf{n}=10)\end{array}$ & $\begin{array}{l}\text { Intra-day } \\
\text { RSD\% } \\
(\mathbf{n}=6) \\
\end{array}$ & $\begin{array}{l}\text { Inter-day } \\
\text { RSD\% } \\
(\mathbf{n}=10)\end{array}$ & $\begin{array}{l}\text { Intra-day } \\
\text { RSD\% } \\
(\mathbf{n}=\mathbf{6}) \\
\end{array}$ & $\begin{array}{l}\text { Inter-day } \\
\text { RSD\% } \\
(\mathbf{n = 1 0 )} \\
\end{array}$ & $\begin{array}{l}\text { Intra-day } \\
\text { RSD\% } \\
(\mathrm{n}=6)\end{array}$ & $\begin{array}{l}\text { Inter-day } \\
\text { RSD\% } \\
(\mathbf{n}=10)\end{array}$ \\
\hline MC-RR & 6.9 & 4.8 & 11.2 & 14.5 & 15.4 & 16.0 & 13.5 & 13.9 \\
\hline NOD & 7.6 & 9.2 & 6.9 & 11.2 & 8.2 & 8.5 & 7.5 & 7.7 \\
\hline MC-YR & 4.5 & 6.8 & 6.2 & 10.8 & 9.4 & 6.2 & 5.4 & 6.6 \\
\hline MC-LR & 4.8 & 6.4 & 4.4 & 4.9 & 8.1 & 9.6 & 6.1 & 7.9 \\
\hline MC-WR & 3.9 & 5.4 & 5.9 & 7.1 & 11.3 & 12.8 & 12.2 & 10.6 \\
\hline MC-LA & 5.7 & 5.3 & 5.5 & 7.3 & 9.8 & 6.5 & 6.8 & 8.8 \\
\hline MC-LY & 5.7 & 6.4 & 7.4 & 6.7 & 8.5 & 9.2 & 13.0 & 11.1 \\
\hline MC-LW & 4.3 & 6.4 & 5.9 & 8.7 & 8.8 & 11.7 & 7.1 & 10.6 \\
\hline MC-LF & 4.3 & 4.4 & 9.1 & 8.0 & 12.0 & 10.6 & 10.2 & 12.1 \\
\hline
\end{tabular}

Level 1A: $15.0 \mu \mathrm{g} \mathrm{L}^{-1} \mathrm{MC}-\mathrm{RR}$, YR, LR, WR, LA, LY, LW, LF, and NOD Level 2A:30.0 $\mu \mathrm{g} \mathrm{L}^{-1} \mathrm{MC}-\mathrm{RR}, \mathrm{YR}, \mathrm{LR}, \mathrm{WR}, \mathrm{LA}, \mathrm{LY}, \mathrm{LW}, \mathrm{LF}$, and NOD Level 1B:0.5 $\mu \mathrm{g} \mathrm{L}^{-1} \mathrm{MC}-\mathrm{RR}, \mathrm{LA}, \mathrm{LF}$, and NOD, $1.25 \mu \mathrm{g} \mathrm{L}^{-1} \mathrm{MC}-\mathrm{YR}$, LR, WR, LY, and LW Level 2B:2.0 $\mu \mathrm{g} \mathrm{L}^{-1} \mathrm{MC}-\mathrm{RR}, \mathrm{LA}, \mathrm{LF}$, and NOD, 5.0 $\mu \mathrm{g} \mathrm{L}^{-1} \mathrm{MC}-\mathrm{YR}, \mathrm{LR}, \mathrm{WR}, \mathrm{LY}$, and LW 